\title{
Effects of Different Bioactivator Applications on Fruit Quality and Plant Growth in Strawberry
}

\author{
Sevinc Sener \\ Akdeniz University, Agricultural Faculty, Department of Horticulture \\ 07070, Konyaalti, Antalya, Turkey \\ E-mail: ssener@akdeniz.edu.tr
}

\begin{abstract}
Strawberry cultivation is important for human health and nutrition. Due to the high profit margin, it is one of the important agricultural production branches in the world and in our country, whose cultivation is rapidly increasing and has no marketing problems. When compared with the major strawberry producing countries, it is seen that the average yield of our country is quite low. increasing strawberry productivity is important for agricultural production and national economy. This study was conducted to determine the effectiveness of different plant bioactivators in order to contribute to increase yield and quality in strawberry cultivation. The experiment was carried out in the research and application area of Akdeniz University Faculty of Agriculture between 2018-2019 in a glass greenhouse without climate control, with two seasons (Fall and Spring) and three replications. In the study, Messenger, Crop-set and ISR-2000, which are obtained from commercial companies, were used as bioactivator and neutral day cultivar 'Albion' strawberry was used as plant material. In order to evaluate the effects of applications on vegetative development criteria, stem diameter, plant height, number of leaves and the relationship of these variables with each other were determined. In order to determine the effects of applications on fruit quality; fruit firmness $(\mathrm{kg})$, fruit weight $(\mathrm{g})$, fruit diameter $(\mathrm{mm})$, fruit length $(\mathrm{mm})$, TSS $(\%), \mathrm{pH}$ was determined. When the results obtained were evaluated, statistical differences were determined between the bioactivator applications and control applications in terms of different criteria. At the end of the study, the highest fruit weight $(17.22 \mathrm{~g})$ and length $(40.65 \mathrm{~mm})$ average value obtained from Crop-set application, the highest fruit diameter $(31.73 \mathrm{~mm})$ and fruit firmness $(0.56 \mathrm{~kg})$ from Messenger application while the highest TSS value (7.70\%) was obtained from ISR-2000 application.
\end{abstract}

Keywords: Biostimulator, Plant activator, Fruit quality, Berry

DOI: $10.7176 / J S T R / 5-11-11$

\section{Çilekte Farklı Biyoaktivatör Uygulamalarının Meyve Kalitesi ve Bitki Gelişimi Üzerine Olan Etkileri}

\begin{abstract}
Özet
Çilek yetiştiriciliği, hem çileğin insan sağlığı ve beslenmesi açısından önemi dolayısıyla hem de karlı bir yatırım kolu olması dolayısıyla dünyada ve ülkemizde yetiştiriciliği hızla artan önemli tarımsal üretim kollarından birisidir. Önemli çilek üreticisi ülkeler ile kıyaslandığında ortalama verimi hayli düşük olan ülkemizin çilek verimliliğinin arttırılması tarımsal üretim ve ülke ekonomisi açısından önem arz etmektedir. Bu çalışma çilek yetiştiriciliğinde verim ve kalitenin arttırılmasına katkı sunmak amacıyla ve farklı bitki biyoaktivatörlerinin etkinliğini belirlemek amacıyla yürütülmüştür. Deneme 2018-2019 yılları arasında Akdeniz Üniversitesi Ziraat Fakültesi Araştırma ve Uygulama Arazisinde örtüaltı koşullarda yürütülmüştür. Çalışmada biyoaktivatör olarak ticari firmalardan temin edilen Messenger, Crop-set ve ISR-2000 isimli preparatlar kullanılırken, bitkisel materyal olarak nötr gün çeşidi olan 'Albion' çilek çeşidi kullanılmıştır. Uygulamaların bitkilerin vejetatif gelişim kriterlerine olan etkilerinin incelenmesi amacıyla bitkilerde gövde çapı, bitki boyu, yaprak sayısı ile bu değişkenlerinin birbirleriyle olan ilişkileri belirlenmiştir. Uygulamaların meyve kalitesine olan etkileri belirleyebilmek amacıyla ise meyvelerde;
\end{abstract}

93 | P a g e

www.iiste.org 
meyve eti sertliği $(\mathrm{kg})$, meyve ağırlı̆̆ $(\mathrm{g})$, meyve çapı $(\mathrm{mm})$, meyve boyu (mm), SÇKM (\%), pH tayini yapılmıştır. Elde edilen sonuçlar değerlendirildiğinde, biyoaktivatör uygulamaları ve kontrol uygulaması arasında farklı kriterler açısından istatistiksel farklılıklar tespit edilmiştir. Çalışma sonunda en yüksek meyve ağırlığ 1 (17.22 g) ve meyve boyu (40.65 mm) ortalama değeri Crop-set uygulamasından, en yüksek meyve çapı $(31.73 \mathrm{~mm})$ ve meyve eti sertliği $(0.56 \mathrm{~kg})$ Messenger uygulamasından elde edilirken en yüksek SÇKM değeri (\%7.70) ISR-2000 uygulamasından elde edilmiştir.

Anahtar Kelimeler: Biyostimulator, Bitki aktivatörü, Meyve kalitesi, Üzümsü meyve

\section{Giriş}

Çileğin (Fragaria x ananassa Duch.) kültüre alınması yaklaşık olarak 250 yıl öncesine tekabül etmektedir (Darrow, ${ }^{1966)}$. Pazarlama sorunu olmayan üzümsü meyve türlerinden birisi olan, hemen hemen her ülkede, farklı iklim koşullarında hatta tropik ülkelerin yüksek yerlerinde yetiştirilebilen çilek bitkisinin dünyadaki toplam üretim değeri 9.223.815 ton'a ulaşmıştır. Bu üretimin 400.167 ton miktarı ise Türkiye tarafından karşılanmaktadır. Toplam 153.920 da çilek üretim alanı olan Türkiye'nin ortalama verimi ise 2.59 ton/da'dır. Üretim miktarı bakımından dünyanın beşinci sırasında olan Türkiye'nin ortalama verim düzeyinin ise diğer bazı ülkelere kıyasla oldukça düşük olduğu görülmektedir. Türkiye'nin ortalama verimi, her ne kadar 2.33 ton/da oranında olan dünya veriminin üzerinde bir sayıya sahip olsa da benzer iklim özelliklerine sahip birçok ülkenin ortalama veriminin altında kalmaktadır (FAO, 2019). Bu rakamlarla kıyaslandığında ülkemizin çilek veriminin bir hayli düşük olduğu söylenebilir. Son yıllarda tarım alanlarının giderek azalması, çileğin aynı yerde uzun yıllar yetiştiriciliğinin yapılması, çevreye ve insan sağlığına olan zararları nedeniyle kullanımı yasak olan metil bromid kadar etkili alternatif toprak fumigantının olmaması, iklim değişikliği, küresel ısınma gibi sebeplerle çilek üretim alanlarında sıkıntılar ortaya çıkmakta, kalitede düşüşler yaşanmakta ve dolayısıyla çilek üretiminde verim düşebilmektedir. Çilek, beslenme açısından büyük bir öneme sahip olmasına, ekonomik getirisinin yüksek olmasına, farklı tüketim şekillerinin olmasına ve aile işletmeciliğine uygun bir kültür bitkisi olmasına rağmen ortalama verimi hala istenilen seviyede değildir. Bunun durumun başlıca nedenleri, biyotik ve abiyotik stres koşullarına hassasiyetin yanı sıra verimi arıttırabilecek modern yetiştiricilik yöntemlerinin uygulanamaması olarak sıralanabilir.

Abiyotik stres toleransını veya ürün kalitesini ve özelliklerini geliştirmek amacıyla uygulanan ve dünya pazarı yaklaşık olarak her yı1 \%12 büyümeyle göstererek 2018 yılı itibarı ile 2,200 milyon dolara ulaşan biyoaktivatörler veya biyostimulantları, mikrobiyal preparatları, hümik ve fülvik asitleri, protein hidrolizatları ve aminoasitleri ve yosun ekstraklarını içerebilen preparatlar olarak tanımlanabilmektedirler (du Jardin 2015; Calvo ve ark., 2014). Higa ve Wididana (1989) tarafindan yapılan çalışmada Lactobacillus aşılanan topraklarda yetiştirilen domates bitkisinden, kontrol parsellerine kıyasla \%51,8, kimyasal gübre uygulanan parsellere kıyasla ise $\% 37,2$ oranında daha yüksek pazarlanabilir meyve elde edildiği bildirilmiştir. Spinelli ve ark. (2010) tarafından yürütülen deniz yosunu özleri içeren Actiwave, isimli ticari biyoaktivatörün çilekte bitki büyüme ve gelişmesini (\%10), yaprak klorofil içeriğini (\%11), stoma yoğunluğunu (\%6.5), fotosentez oranını ve meyve üretimini (\%27) ve meyve ağırlığını arttırdığı bildirilmiştir. Ayrıca preparatın bitki biyo kütlesi üzerinde önemli düzeyde etkili olduğu, gövde kuru madde oranını \%27'ye kök kuru madde oranını ise \%76'ya yükselttiği bildirilmektedir.

$\mathrm{Bu}$ çalışma örtüaltı çilek yetiştiriciliğinde verim ve kalitenin arttırılmasına katkı sunmak amacıyla Messenger, Crop-Set ve ISR-2000 isimli organik tarım sertifikalı ticari bitki biyoaktivatörlerinin çileğin büyüme ve gelişme kriterlerine ve meyve kalitesine olan etkisini belirlemek amacıyla yürütülmüştür.

\section{Materyal ve Metod}

Deneme 2018-2019 yılları arasında Akdeniz Üniversitesi Ziraat Fakültesi Araştırma ve Uygulama Arazisinde iklim kontrolsüz cam serada 5 l'lik plastik saksılarda, 15 Ekim 2018 ile 10 Haziran 2019 tarihleri arasında yürütülmüştür. Albion çeşidine ait frigo fideler 1:3 oranında bahçe toprağ1, torf ve perlit kullanılarak hazırlanan ortamlara dikilmiştir. Deneme 4 faktör (Messenger, Crop-set, ISR-2000 ve Kontrol) ve 4 tekerrür olacak şekilde planlanmış, her uygulamada 10 bitki yer almıştır. Çalışmada, bitkisel materyal olarak nötr gün çeşidi olan 'Albion' çilek çeşidi kullanılmıştır. Albion, gün nötr özelliğinde, iri meyveli çok yıllık yetiştiriciliğe uygun, hibrid, iri sert, konik biçimli, şeker oranı yüksek ve yoğun lezzetli bir çilek çeşididir. Yediveren olarak da adlandırılan bu çeşit orijinal lokasyonunda üretime ilkbahar sonunda başlamakta ve sonbahar sonuna kadar devam etmektedir. Albion çeşidi

94 | P a g e

www.iiste.org 
Verticillium solgunluğu, Phytophthora ve antraktoz meyve çürüklüğüne karşı dayanıklıdır (Türemiş ve Ağaoğlu, 2013).

Çalışmada biyoaktivatör olarak ticari firmalardan temin edilen Messenger, Crop-set ve ISR-2000 isimli preparatlar kullanılmıştır. SAR aktivatörü olarak geliştirilen ve yapraklar üzerinde oluşturduğu ince tabaka sayesinde patojenlerin dokular içerisine girișini zorlaştırdığı bildirilen ISR-2000 preparatı, etiket bilgilerine göre Lactobacillus acidophilus $(855,81 \mathrm{~g} / \mathrm{l})+$ maya ekstrakt1 $(140,97 \mathrm{~g} / \mathrm{l})+$ bitki ekstrakt1 $(111,00 \mathrm{~g} / \mathrm{l})+$ benzoik asit $(2,22 \mathrm{~g} / \mathrm{l})$ içermektedir. Crop-set preparatında ise ISR-2000'den farklı olarak Lactobacillus acidophilus (893,80 g/l) )+bitki ekstraktı $(147,15 \mathrm{~g} / \mathrm{l})$ içeriğine ilave olarak, manganez sülfat $(27,25 \mathrm{~g} / \mathrm{l})+$ demir sülfat $(16,35 \mathrm{~g} / \mathrm{l})+$ bakır sülfat $(5,45 \mathrm{~g} / \mathrm{l})$ bulunmaktadır. Çalışmada kullanılan diğer bir preparat olan Messenger aktif madde olarak \%3 oranında harpin içermektedir.

Çalışma süresinde uygulamaların bitki gelişimine ve meyve kalitesine olan etkisini tayin edebilmek amacıyla haftalık olarak bitkilerde boy, çap ve yaprak sayısı ölçümleri yapılmıştır. Bitkilerde meyve oluşumunu takiben ise meyvelerde meyve eni ve boyu, meyve ağırlığı, meyve eti sertliği, pH ve SÇKM ölçümleri yine haftalık olarak tayin edilmiştir. Elde edilen veriler SPSS 23 paket programında $\mathrm{P} \leq 0.05$ önem düzeyinde değerlendirilmiştir.

\section{Bugular ve Tartışma}

Deneme boyunca farklı biyoaktivatör uygulamalarının bitkilerin büyüme parametreleri üzerine olan etkilerini tayin edebilmek amacıyla haftalık olarak bitkilerde boy, çap ve yaprak sayısı ölçümleri yapılmış ve elde edilen verilerin aylara göre ortalaması Şekil 1, Şekil 2 ve Şekil 3'de sunulmuştur.

Şekil 1'de biyoaktivatör uygulamalarının farklı aylarda yapılan bitki boyu ölçümü ortalama değerlerine olan etkisi görülmektedir. Grafikte sunulan veriler incelendiğinde, Şubat $(11,48 \mathrm{~cm})$ ve Mayıs $(28,82 \mathrm{~cm})$ ayında en yüksek ortalama değerin Crop-set uygulamasında, Mart ayında ISR-2000 (15,60 cm) uygulamasında, Nisan ayında ise Messenger $(26,16 \mathrm{~cm})$ uygulamasında belirlendiği görülmektedir. En düşük ortalama değerler ise tüm ölçümlerde kontrol (Şubat; $9.22 \mathrm{~cm}$, Mart; $13.73 \mathrm{~cm}$, Nisan; $17.95 \mathrm{~cm}$, Mayıs; $17.65 \mathrm{~cm}$ ) uygulamasında belirlenmiştir.

Biyoaktivatör uygulamalarının Albion çilek çeşidinde gövde çapına olan etkileri Şekil 2'de sunulmuştur. Elde edilen veriler incelendiğinde bitki boyundan elde edilen ortalama değerlere benzer şekilde tüm ölçümlerde en düşük ortalama değerlerin kontrol (Şubat; 13.76 mm, Mart; 20,35 mm, Nisan; 21.59 mm, Mayıs; $22.32 \mathrm{~mm}$ ) uygulamasında tayin edildiği görülmektedir. En yüksek değerlerin ise Şubat (15.35 $\mathrm{mm})$, Nisan $(30.41 \mathrm{~mm})$ ve Mayıs $(32.03 \mathrm{~mm}$ ) aylarında Messenger uygulamasından elde edildiğ $\mathrm{i}$ görülmektedir. Mart ayında ise diğer aylardan farklı olarak en yüksek ortalama değer ISR-2000 (22.40 mm) uygulamasında belirlenmiştir. Köksal ve ark., (2017) 'Albion' ve 'Sweet Charlie' çilek çeşitlerine ait fideleri farklı boyutlardaki saksılarda yetiştirmiş ve çalışma sonunda Albion çeşidinin ortalama yaprak sayısını 5,11 (adet /bitki), kök boğazı kalınlığ 1 ise 9,86 mm olarak bildirmişlerdir.

Yetiştirme sezonu süresince uygulamaların bitkilerin vejetatif gelişimine olan etkisini tayin etmek amacıyla haftalık olarak belirlenen bitki boyu, gövde çapı ve yaprak sayısı ölçümlerinin ortalamaları Tablo 1'de sunulmuştur. Yapılan istatistik analizlere göre uygulamalar arasında incelenen tüm kriterler bakımından önemli düzeyde farklar tespit edilmiş, biyoaktivatör uygulamasının bitki boyu, gövde çapı ve yaprak sayısına, kontrole kıyasla pozitif yönde etki ettiği belirlenmiştir. Bitki boyu (Messenger; 18.13 cm, Crop-set; 19.49 cm, ISR-2000; $18.58 \mathrm{~cm}$ ) ve gövde çap1 (Messenger; $25.05 \mathrm{~mm}$, Crop-set; 22.63 mm; ISR-2000; 24.06 mm) bakımından Messenger, Crop-set ve ISR-2000 aynı istatistiksel grupta yer alırken, yaprak sayısı bakımından en yüksek ortalama değer Crop-set (9,59 adet/bitki) uygulamasında belirlenmiştir.

Tablo 1. The capitals, assets and revenue in listed banks

\begin{tabular}{|l|l|l|l|}
\hline $\begin{array}{l}\text { Biyoaktivator } \\
\text { Uygulamaları }\end{array}$ & Bitki Boyu & Gövde Çapı & $\begin{array}{l}\text { Yaprak } \\
\text { Sayısı }\end{array}$ \\
\hline Kontrol & $14,64 \mathrm{~b}$ & $19,51 \mathrm{~b}$ & $6,42 \mathrm{c}$ \\
\hline Messenger & $18,13 \mathrm{a}$ & $25,05 \mathrm{a}$ & $8,78 \mathrm{ab}$ \\
\hline Crop-set & $19,49 \mathrm{a}$ & $22,63 \mathrm{a}$ & $9,59 \mathrm{a}$ \\
\hline ISR-2000 & $18,58 \mathrm{a}$ & $24,06 \mathrm{a}$ & $8,26 \mathrm{~b}$ \\
\hline
\end{tabular}




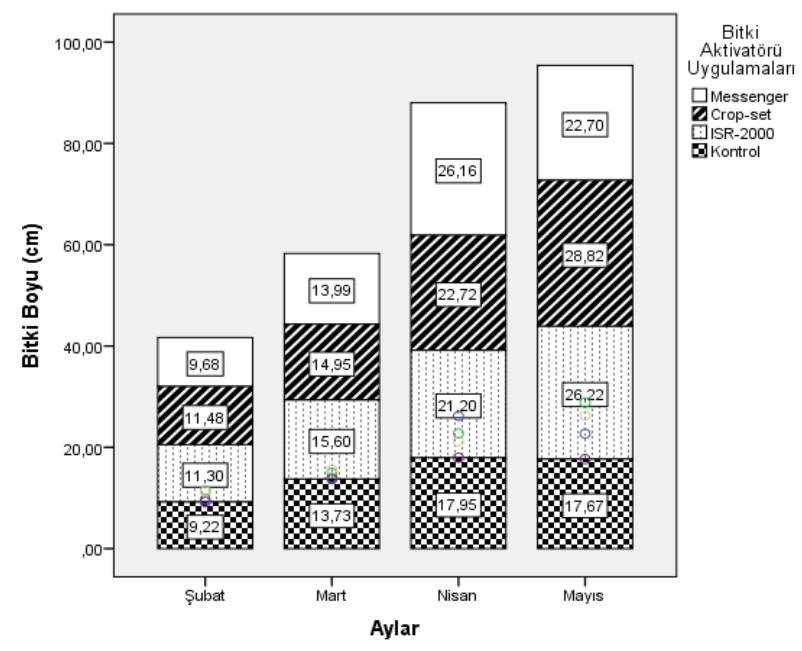

Şekil 1. Farklı biyoaktivatör uygulamalarının çilek bitkisinin bitki boyuna olan etkisi.

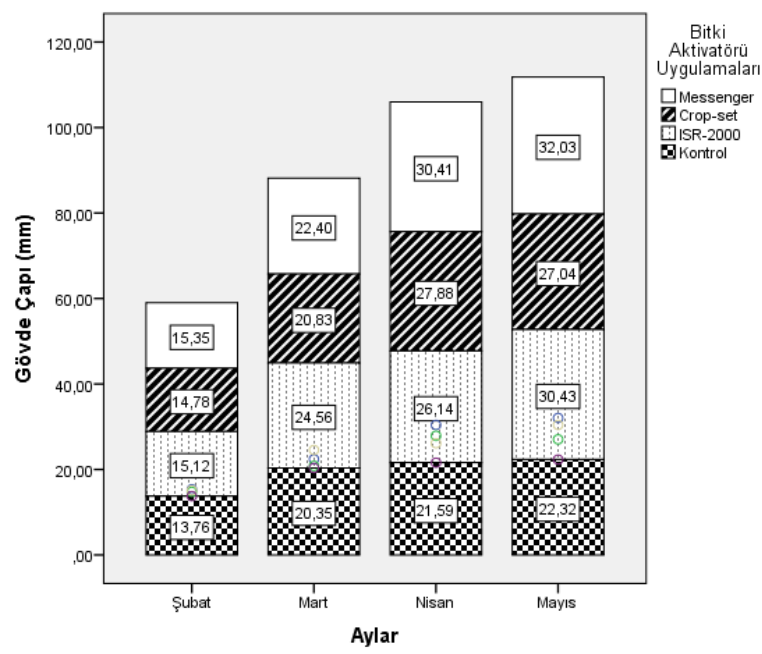

Şekil 2. Farklı biyoaktivatör uygulamalarının çilek bitkisinin gövde çapına olan etkisi.

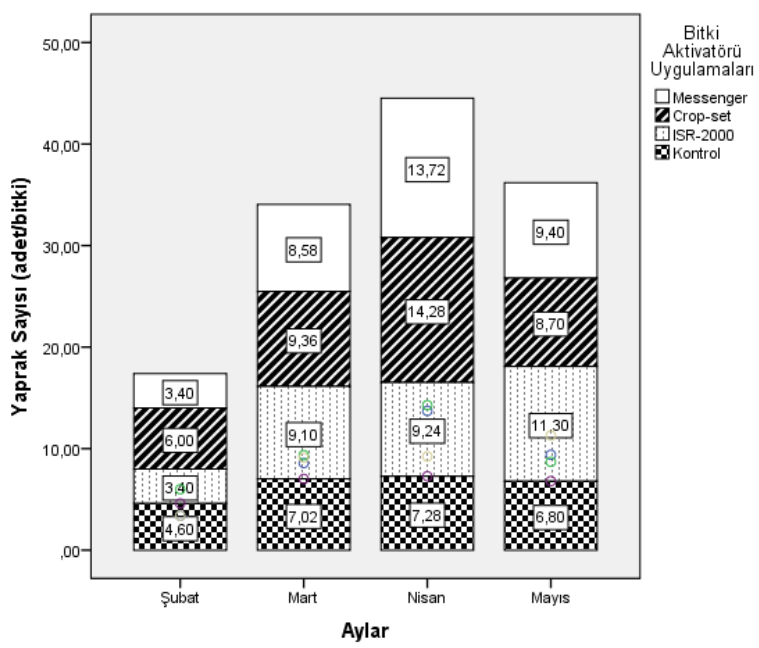

Şekil 3. Farklı biyoaktivatör uygulamalarının yaprak sayısına olan etkisi. 


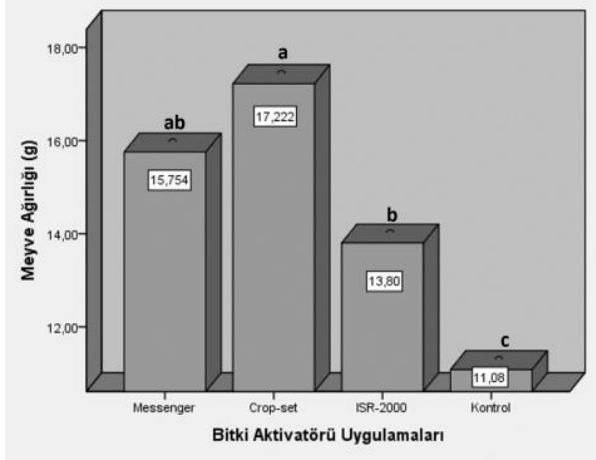

$\mathrm{a}$

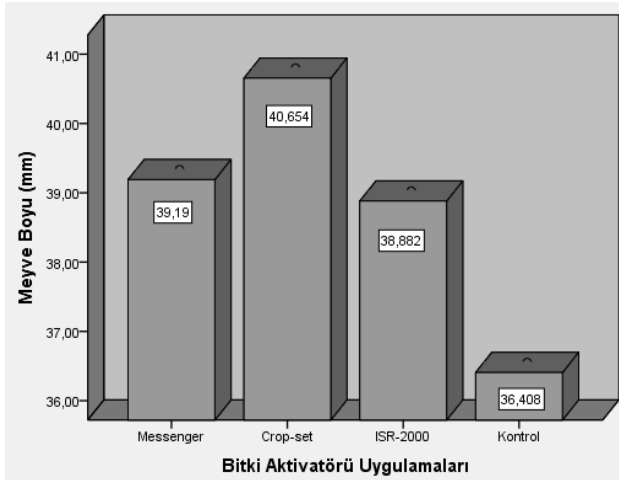

C

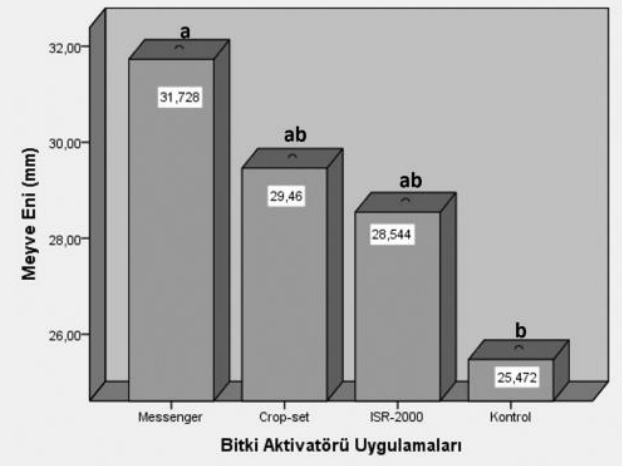

b

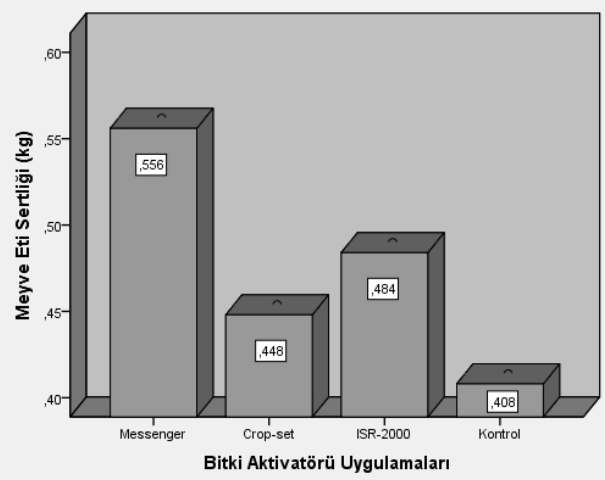

d

Şekil 4. Farklı biyoaktivatör uygulanan çileklerin meyve kalite özellikleri a) Meyve Ağırlığı (g), b) Meyve Eni (mm), c) Meyve Boyu (mm), d) Meyve Eti Sertliği

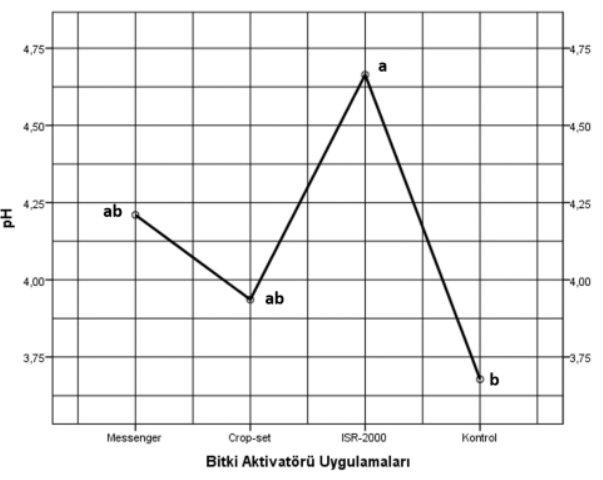

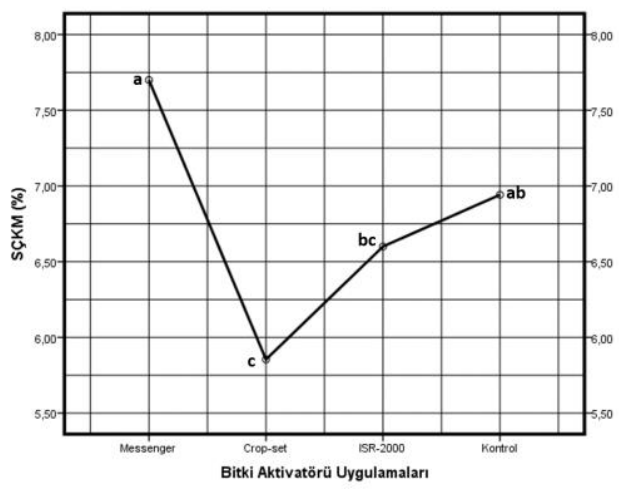

$\mathrm{b}$

Şekil 5. Farklı biyoaktivatör uygulamalarının çileklerin a) pH ve b) SÇKM içeriği üzerine olan etkisi

Örtüaltında güz ve ilkbahar dönemlerinde yetiştirilen Albion çeşidi çileklerden elde edilen bazı meyve özellikleri Şekil 4'de görülmektedir. Biyoaktivatör uygulamalarının Albion çilek çeşidinin meyve ağırlığına ve boyuna olan etkisi değerlendirildiğinde en iyi etkiyi Crop-set (meyve ağırlığı; 17.22 g; meyve boyu; $40.65 \mathrm{~mm}$ ) uygulamasının yaptığı görülmektedir. Meyve eni ve meyve eti sertliği 
bakımından ise en yüksek ortalama değerler $31.73 \mathrm{~mm}$ (meyve eni) ve $0,56 \mathrm{~kg}$ (meyve eti sertliği) ile Messenger uygulamasında tayin edilmiş̧ir. Çekiç ve Aksu (2012) nun Tokat koşullarında bazı çilek çeşitlerinin (Camarosa, Sweet Charlie, Camino Real, Albion) performanslarını belirlemek amacı ile yürütttükleri çalışmada Albion çeşidinin ortalama meyve ağırlığının çalışmamızdan elde edilen ortalama değerlere benzer şekilde 16,4 g (Albion) ile 23,1 g (Albion) arasında olduğunu bildirmişlerdir. Sarıdaş ve ark., (2017) tarafindan yapılan çalışmada farklı sulama seviyeleri ve biyoaktivatör (ComCat) uygulamalarının 'Rubygem' çilek çeşidinde meyve kalite kriterleri üzerine etkileri incelenmiş ve çalışma sonunda çalışmamızdan farklı olarak ComCat biyoaktivatörünün incelenen meyve kalitesi parametreleri (meyve eni, meyve boyu, meyve ağılığı, SÇKM, asitlik) üzerine tek başına etkisi önemsiz bulunmuştur. $\mathrm{Bu}$ durumun kullanılan aktivatörlerin içerik farklılı̆̆ından, iklim ve toprak koşulları farklılığından veya kullanma döneminden kaynaklanmış olabileceği düşünülmektedir.

Şekil 5'de bioaktivatör uygulamalarının çileklerin $\mathrm{pH}$ ve SÇKM içeriği üzerine olan etkileri yer almaktadır. Sunulan grafikler incelendiğinde ortalama $\mathrm{pH}$ ve SÇKM içerikleri arasında istatistiksel farkl11ıkların belirlendiği görülmektedir. En yüksek ortalama pH değeri ISR-2000 4.66 uygulamasında belirlenirken, en yüksek SÇKM değeri ise \%7.70 ile Messenger uygulamasında belirlenmiştir.

Sezer, (2010), Camarosa ve Albion çilek çeşitlerinin organik yetiştiricilik olanaklarını araştırdığı çalışmasında, benzer şekilde Albion çeşidinin ortalama meyve ağırlı̆̆ını 16,4 g, SÇKM içeriğini \% 10,25, $\mathrm{pH}$ değerini 3,70 olarak bildirirken, Mısır, (2016) Albion çeşidinin ortalama meyve ağılığının 12,6 g, SÇKM içeriğinin ise \% 6,8 olarak tespit edildiğini bildirmiştir. Türkoğlu ve Bilgener (2006), farklı bitki aktivatörü uygulamalarının, Selva ve Camarosa çilek çeşitlerinin verim ve meyve kalitesi üzerine olan etkilerini araştırdıkları çalışmalarında, bizim çalışmamızdan farklı olarak bitki aktivatörü uygulamalarının ortalama meyve ağırlığı, SÇKM ve titre edilebilir asit içeriği üzerine olumlu bir etkisi olmadığını bildirmişlerdir. Meyvelerin biyokimyasal içerikleri çeşit farklılığından etkilenebildiği gibi yetiştirme koşulları da etken olabilmektedir.

\section{References}

Calvo, P., Nelson, L., \& Kloepper, J. W. (2014). Agricultural uses of plant biostimulants. Plant and soil, 383(1-2), 3-41.

Çekiç, Ç., Aksu, H.D., 2012. Bazı Çilek Çeşitlerinin Niksar Ekolojisindeki (Kelkit Vadisi) Performansları. IV. Ulusal Üzümsü Meyveler Sempozyumu, 03-05 Ekim 2012, Antalya, s: 340341.

Darrow, G. M. (1966). The strawberry. History, breeding and physiology. The strawberry. History, breeding and physiology.

Du Jardin, P. (2015). Plant biostimulants: definition, concept, main categories and regulation. Scientia Horticulturae, 196, 3-14.

FAO (2019). www.faostat.org (Erişim Tarihi: 12.10.2019)

Higa, T., \& Wididana, G. N. (1991). Changes in the soil microflora induced by effective microorganisms. In Proceedings of the First International Conference on Kyusei Nature Farming. US Department of Agriculture, Washington, DC, USA (pp. 153-162).

Köksal, N., Özkaya, A., Kafkas, E., \& Yasemin, S. (2017). Süs Bitkisi Olarak Çilek Yetiştiriciliğinde Saksı Boyutlarının Etkisi. Bahçe 46 (Özel Sayı 1), 139-148.

Mısır, D. (2016). Bazı çilek çeşitlerinin adaptasyonu. Yüksek Lisans Tezi. On Dokuz Mayıs Üniversitesi, Fen Bilimleri Enstitüsü, Bahçe Bitkileri Anabilim Dalı, Samsun

Sarıdaş, M. A., Kapur, B., Çeliktopuz, E., \& Kargı, S. P. (2017). Irrigation Regimes and Bio-stimulant Application Effects on Fruit Quality Features at 'Rubygem'Strawberry Variety. Turkish Journal of Agriculture-Food Science and Technology, 5(10), 1221-1227. 
Sezer, L. (2010). Mardin ili Kızıltepe ilçesinde organik çilek yetiştiriciliği olanaklarının araştırılması. Yüksek Lisans Tezi. Çukurova Üniversitesi, Fen Bilimleri Enstitüsü, Bahçe Bitkileri Ana Bilim Dalı, Adana.

Spinelli, F., Fiori, G., Noferini, M., Sprocatti, M., \& Costa, G. (2010). A novel type of seaweed extract as a natural alternative to the use of iron chelates in strawberry production. Scientia horticulturae, 125(3), 263-269.

Türemiş, N., \& Ağaoğlu, Y. S. (2013). Çilek. Üzümsü Meyveler (Ed. Ağaoğlu, S. ve Gerçekçioğlu, R.), Ankara Tomurcukbağ Ltd. Şti. Eğitim Yayınları, (1), 55-117.

Türkoğlu, Z., Bilgener, Ş., 2006. Selva ve Camarosa Çilek Çeşitlerinde Bazı Bitki Aktivatörlerinin Erkencilik, Verim, Kalite İle Yapraklardaki Besin Element Düzeylerine Etkileri. II.Ulusal Üzümsü Meyveler Sempozyumu. s: 284-289. 